\title{
Viabilidad de la economía circular en países no industrializados y su ajuste a una propuesta de economías transformadoras. Un acercamiento al escenario latinoamericano
}

\section{Pablo Paño Yáñez}

RESUMEN: En el contexto actual de análisis de los límites de la economía lineal y de propuestas desde las economías transformadoras el presente documento de revisión teórica y proposición, reflexiona sobre su adaptación a países de la periferia y no industrializados de América Latina en particular. Específicamente se plantea: i) el estado del arte y sistematización sobre el contexto de las denominadas como economías transformadoras con especial énfasis en los planteamientos, ámbitos y prácticas de economía circular tanto desde el norte como desde el sur global, incluidas las limitaciones retos que se señalan sobre ella; y ii) esbozar un planteamiento de principios normativos, incluida la circularidad, para economías transformadoras en países latinoamericanos como alternativa estructural a sus determinantes internacionales, ambientales, sociales, culturales y económicos.

PALABRAS CLAVE: Economías transformadoras, Economía circular, circularidad, sustentabilidad fuerte, cobertura necesidades, Buen Vivir.

CLAVES ECONLIT: B5, I31, Q2, Q3, Q5.

Cómo citar este artículo/How to cite this article: PAÑO, P. (2021): "Viabilidad de la economía circular en países no industrializados y su ajuste a una propuesta de economías transformadoras. Un acercamiento al escenario latinoamericano", CIRIEC-España, Revista de Economía Pública, Social y Cooperativa, 101, 289-323. D0I: 10.7203/CIRIEC-E.101.15979.

Correspondencia: Pablo Paño Yáñez, Universidad de Cuenca (Ecuador), pablo.panoy@ucuenca. edu.ec. 


\section{Expanded abstract}

\section{Viability of circular economy in}

nonindustrialised countries and its

adjustment to a proposal based on

\section{transformative economies: an approach to the latin-american scenario}

In response to the evident unsustainably of linear economy a vast array of new concepts regarding the so-called alternative economies has emerged. Along the same line, this paper focuses on analyzing the definitions, applications, and debates over circular economy. The main question being to identify to which extend circular economy can be adapted and respond to the realities and needs of non-industrialized countries' societies in the global South, especially in Latin America. To do so, all main questions in which the so-called reformist and transformationist schools differ have been examined: full reduction of resources, conceptions of sustainability, and even the modification of the capitalist economic order (promoted by transformationists while unreservedly rejected by reformists).

This proposal points out the limits of circular economy regarding unemployment levels, planned obsolescence, or its contribution to dematerialization and decarbonization so as to constitute a viable model. Also, its implementation does not necessarily ensure energy reduction or optimization and material consumption, and it meets with corporate resistance given that its profitability is unclear. These debates show the diversity and ambivalence of approaches and practices regarding alternative economies. Societies such as those in Latin America should examine how these economies are shaped to provide a real alternative adapted to local needs.

Firstly, this article provides a state of the art through the review and contrast of multiple alternative approaches to the economy, coming from different parts of the globe with different politico-economic realities (care economy, ecological economy, economy of life, sustainability, sharing economy, degrowth, popular economy, the Common, etc.). Secondly, it aims to lay the foundations for a useful proposal tailored to countries and economies that are not rich nor industrialized but show high levels of inequality, social injustice, and serious external and internal threats regarding ecological sustainability.

The results reveal that in several territories in the South some rooted circular economy practices already exist (higher rates of re-utilization and repair as well as lower consumption, which equates to reduction). Urban recycling together with agriculture and livestock farming (especially with agroecology and permaculture initiatives) provide livelihood to many people through popular economy and, in some cases, through social economy. All the above is signif- 
icantly connected to Latin American conceptions regarding development, such as Buen Vivir, which deviate from a rational, productivist logic and offer alternative approaches to social justice and to living in harmony with nature.

This proposal was outlined after an in-depth analysis of various results. One specific conclusion is that the concept of circularity is especially useful to lay down the guidelines of transformative economies for societies in the South as long as it is associated to a number of other premises.

All these guidelines can be summarized as follows: coverage of basic human needs; strong sustainability; relevant reduction of extractivisms, popular economy/social economy, socio-economic and ecological democracy; inclusive, predistributive and fair in nature; inspired by nature, ancestral communities and other productivities; strengthening of internal and local economy linked to higher scales of economy, and finally, useful, dignified, collaborative, universal employment.

From a substantial perspective that considers economy as being strictly linked to two larger systems (the society and the environment that contain it), this proposal offers a change in direction regarding the menace of unsustainability and social injustice imposed by the dominant economy (dissociated from the natural and social environment) and more patently visible in peripheral societies in the South rather than in core countries.

This theoretical proposition attempts to address an issue and its existing approaches although it draws on practices that we have not directly investigated. It its therefore inevitably generic in nature and for specific applications it should be adapted to concrete ecological, sociopolitical, and economic contexts of unindustrialized societies in the South. Likewise, it sets out guidelines on indicators for the identification of sustainability, circularity, coverage of needs and social justice, which should be operationalized according to these different contexts. Still, this proposal was conceived as the theoretical and conceptual framework of a current investigative process in Ecuador on specific areas such as electronic waste management, polymers reuse, or the role of recyclers; in that sense, its purely theoretical nature is left behind as it is a key part of a set of larger joint actions.

The originality of the present work relies on the manner that it connects all the concepts and debates over alternative economies -and their relation to the dominant economy- with the reality of unindustrialized countries of the global South. Importing these unadjusted models translates into unsuccessful efforts -often from public institutions- since they lack social, cultural, and economic contextualization, among others.

In this sense, this comprehensive and contextualized proposal sets up the necessary guidelines for transitioning from a dominant model to alternative forms of economy.

Keywords: Transformative economies, circular economy, circularity, strong sustainability, coverage of needs, Buen Vivir. 


\section{Introducción}

La economía circular como neoconcepto reciente es nombrada cada vez en mayor medida a nivel global. Especialmente desde la Unión Europea y China como zonas altamente industrializadas se vienen destinando recursos significativos en investigación y experimentación que ayude a la superación de una economía lineal que, aunque todavía dominante, aparece cuestionada debido a sus crecientes manifestaciones de insustentabilidad. Las razones son contundentes ante las múltiples expresiones del cambio climático y amenazas de colapso ambiental, la evidencia del agotamiento de los materiales así como, de la crisis energética del petróleo como principal energía utilizada y en cuyo descenso ya se encuentra la humanidad desde 2006. Ello con la implicación de importantes amenazas ecológicas que, según cada vez más autores, no se están dimensionando en toda su profundidad desde la mayoría de análisis y propuestas. La altísima capacidad energética demostrada en las últimas décadas no tiene posibilidad de mantenimiento, incluso aunque se alcanzara una adecuación significativa de energías renovables más sustentables. Habría correspondido a una etapa de clara extralimitación del modelo económico de extracción y consumo sin posibilidad de réplica y que exige alternativas viables en un futuro próximo.

El cambio necesario pone en debate algunos de los fundamentos del modelo actual exigiendo la transición y resignificación de conceptos como el de crecimiento o desarrollo. Bajo la lógica lineal de crecimiento se convirtió en indispensable la constante extracción de nuevas materias primas. La linealidad que lo caracteriza aparece acompañada de un alto volumen de consumo diverso de productos y energía, además de la externalización de sus costes ambientales y sociales. Por tanto, los altos índices de extracción para posibilitar un modelo masivo de consumo con carácter desechable en un planeta finito con cada vez más población, estaría provocando que se esté próximo al límite de dicho planteamiento por mucho que hasta la actualidad haya resultado y resulte rentable a sus promotores. A modo de ejemplo: son más de 20 los elementos minerales fundamentales en el modelo productivo actual, muy próximos a su agotamiento y que además, se desconoce en más de un $90 \%$ dónde se halla el que ha sido utilizado (Cerantola, 2019); entre ellos el oro, la plata, el zinc o el antimonio.

Planteado como un sistema cerrado y pequeño, la economía clásica actual situada como regente por fuera de la sociedad y la política, y marcada por una racionalidad instrumental (Coraggio, 2014) con carácter lineal, no asume los múltiples impactos socioambientales que genera. Ello bajo la construcción racionalista de una naturaleza que ha sido cosificada, desnaturalizada de su complejidad ecológica y convertida en materia prima de un proceso económico (Leff et al., 2003).

En el debate sobre el concepto de desarrollo y sus implicaciones, autores como Trainer (2017, p. 163) definen como alternativa a este último, uno que tenga como objetivo satisfacer el grueso de las necesidades básicas y promover una calidad de vida aceptable para todo el mundo; y considera que para ello habitualmente los recursos están en los territorios, así como que se necesita poco o ningún capital monetario. 
Precisamente la revisión y deconstrucción de ese modelo lineal y de sus fundamentos de la mano de la evidencia de su inviabilidad actual, nos sitúan en el escenario de las propuestas de las denominadas economías transformadoras (Suriñach, 2016), entre las cuales el presente documento se plantea como objetivo analizar la economía circular respecto a sus debates orientados a la viabilidad de su implementación en países bajamente industrializados y parte de la periferia del sistema-mundo económico (Wallerstein, 2014). En este documento se analizan casos de países de América Latina a modo de referencia de lo que son estados-nación no situados en el centro de la economía mundo sino en su periferia. Ante las múltiples nomenclaturas ordenadoras de los países del planeta respecto a sus economías y/o la estructura que los ordena (Ricos y pobres; Desarrollados y subdesarrollados; Primer y Tercer Mundo; Enriquecidos y empobrecidos; Con alto o bajo IDH; Centro y Periferia, Norte Global y Sur Global, Clase deudora global y Clase acreedora global, entre otros (Mosangini, 2012), pese a que ninguno sea del todo preciso para el tema analizado, se opta por el cruce entre los que se remiten a su industrialización, su ubicación en estructura de la economía mundo y constituir esa ordenación Norte Global y Sur Global. Aun señalada como zona geográfica, América Latina constituye con claridad un ejemplo de ser territorios ex-coloniales que quedaron situados desde entonces en la periferia de la economía mundo y Sur Global, así como no habría vivido, pese a intentos, procesos significativos de industrialización, factores que desde lo político, geoestratégico, económico y productivo, resultan determinantes para la comprensión de su ubicación ante el modelo económico dominante y su posibilidad de implementar procesos de las que se denominan como economías transformadoras. Todo lo anterior, sin olvidar a su vez las agudas desigualdades internas de sus países y territorios que confirman la idea de que existe un Norte en el Sur y un Sur en el Norte.

Ante los imperantes evidentes de la insustentabilidad de la economía lineal, surge desde sectores de países de la periferia/no industrializados/Sur Global la pregunta sobre la viabilidad de poder implementar modelos económicos transformadores entre los que se incluya la economía circular; de cómo caracterizarla y ajustarla a la realidad ambiental, social, cultural y económica de sus países y territorios, y a partir de ahí, cómo hacerla factible. Así, dilucidar los pilares sobre los que edificar una(s) economía(s) alternativa(s) para países latinoamericanos como parte de la periferia no industrializada, así como pautar criterios principales para a futuro construir indicadores que orienten su consumación, constituyen los objetivos específicos. 


\section{Alternativas desde las economías transformadoras desde Centro y Periferia. La economía circular como propuesta específica}

\subsection{Movimientos y fenómenos al interior de las economías transformadoras}

En las últimas décadas se ha intensificado el cuestionamiento a la economía de carácter lineal, surgiendo múltiples tipos de prácticas, análisis y alternativas. Desde Europa Autores como Suriñach (2016) distinguen entre movimientos y fenómenos relacionados con las economías transformadoras, distinción que acogemos de forma flexible para este análisis aunque ampliándolo a escenarios no solo del Norte sino también del Sur global, especialmente de América Latina.

En cuanto a los movimientos, escuelas o corrientes entendidos como con una base y proyecto social común con intención de incidir en la esfera pública, encontramos múltiples expresiones; se puede señalar que desde su diversidad tienen en común los serios cuestionamientos al modelo y el enfoque liberal dominante.

Desde América Latina, algunos autores se refieren directamente a la economía de la vida o a la sustentabilidad de la vida. Hinkelammert \& Mora (2014) abordan críticamente la economía de mercado por sus insuficiencias para la cobertura de las necesidades humanas y plantean desde ahí las vías para el retorno a formas sustantivas de economía. Max Neef (2017) confirma la idea de economía para la vida como aquella absolutamente vinculada a los ecosistemas bajo una concepción de desarrollo que no pase por el crecimiento. Pareciera existir conexión con algún discurso político reciente en América Latina (Gustavo Petro) que distingue entre las que denominan como economía de la vida y economía de la muerte, ésta especialmente vinculada a los extractivismos de muy alto impacto social y ambiental en el subcontinente.

Como movimientos para América Latina hallamos principalmente los de economía popular y economía solidaria (Quijano, 2011) que aglutinan un amplio y extendido espectro de prácticas de producción y organización económica para amplios sectores populares de sus sociedades.

Otras propuestas de ellos proceden de Europa, aunque a menudo tienen visión global y sistémica. Una primera con significativo aporte a ese debate es la economía ecológica (Martínez Alier \& Roca, 2016) que inserta la economía en el contexto de la ecología. Rebate muchos de los preceptos de la economía tradicional liberal que confundiría valor y precio, así como pone énfasis en identificar la externalización de costes ambientales que la economía ortodoxa no cuantifica. Dichas externalizaciones demuestran que el mercado como un marco restringido 
y definido fuera de la sociedad y el medio que lo alberga, y sobre los que produce constantes impactos, no puede hacer una asignación eficiente ya que los constantes perjuicios sobre la naturaleza no tienen precio en él; de hecho, las externalizaciones distorsionan precios de éste rebajándolos ampliamente por el hecho de no contabilizarlos crematísticamente. Esos precios en el mercado serían radicalmente diferentes si se contabilizaran la totalidad de costes tanto productivos como, especialmente, sociales y medioambientales que realmente implican.

También cobran fuerza las denominadas diferenciadamente economías de los comunes, del pro-común y del bien común. Autores como el reciente premio nobel de economía Tirole (2017) señalan que son dos los campos de esos impactos negativos: los medioambientales con amenazas objetivas que ponen en jaque tanto el capitalismo como los conceptos de crecimiento económico (Ramos, 2015), desarrollo y progreso (Klein, 2015), y los sociales, históricamente centrados en el debate de la distribución y las condiciones de trabajo. Laval \& Dardot (2014) son otros de los que analizan los denominados bienes comunes, diferenciándolos de los privados y los públicos, y cómo ellos históricamente existentes en las sociedades, constituyen alternativas sobre las que (re)construir economías sustentables más justas social y ecológicamente.

Otra propuesta relevante como movimiento, además de larga trayectoria, es la denominada como economía social que conforma un espacio de la realidad económica integrado por formas organizativas privadas creadas por personas para dar respuesta a sus propias demandas sociales, a sus problemas sustantivos y a sus aspiraciones sociales. Las formas de economía social constituyen respuestas de la sociedad civil organizada a las demandas y problemas que no han encontrado respuestas satisfactorias ni por parte del Estado y las administraciones públicas ni por parte del sector empresarial tradicional (Chaves \& Monzón, 2018). Una de las expresiones más desarrolladas y exitosas en su interior serían diverso tipo de cooperativas con trayectorias y formas organizativas muy diversas a lo largo del mundo (Suriñach, 2016). Santos \& Rodríguez (2011) destacan la inspiración del cooperativismo en valores de autonomía, democracia participativa, igualdad, equidad y solidaridad. Desde y para América Latina Coraggio (2016), profundizará ampliamente en su caracterización señalando como básicas: la producción racional de bienes y servicios bajo formas pilares de organización, la relación restitutiva entre trabajo y naturaleza, la distribución y redistribución de la riqueza producida, el intercambio justo y reciprocidad, el consumo responsable con la naturaleza y la convivencia, y la coordinación democrática durante el conjunto del proceso económico.

Asimismo, han cobrado especial relevancia en la última década las economías feministas y/o ecofeminismo (Pérez Orozco, 2017); rechazan la idea que la economía es solo la monetaria que está dentro del mercado que excluye los procesos naturales y sociales que se sitúan detrás de cualquier acción económica. Así, definen la economía como los diversos procesos de sostenibilidad de la vida, enfatizando en hacer visibles todos aquellos trabajos y tareas históricamente invisibilizadas, asociadas a las mujeres, y que son la base del sostenimiento de la vida; finalmente sitúa el género como variable clave, así como hace visible que las relaciones de género llevan implícitas unas relaciones de poder y unas desigualdades que son un eje estructural del sistema económico. Pérez Orozco (2015) explicita una abierta incompatibilidad 
entre capital y vida del que derivan otras articuladas: el conflicto entre trabajo y capital, que a su vez derivan en aquella entre el crecimiento y los límites biofísicos del planeta.

Otro movimiento relevante asociado a prácticas es la denominada como economía colaborativa (Belda, 2018) aunque existan dos versiones sobre ella (Chaves \& Monzón, 2018): como movimiento ciudadano e institucional desde la Unión Europea. Ambas encuentran su idea central en compartir recursos en vez de poseerlos ya que ello permite un uso más eficiente. La institucional como corriente muy reciente guarda un estrecho vínculo con las nuevas tecnologías de información y comunicación en la medida que estas serían el medio principal para acceder a bienes y servicios, promoviendo para las nuevas plataformas tecnológicas la potencialidad de generar relaciones económicas entre iguales y, por tanto, de generar nuevas lógicas de consumo, trabajo, gobierno, entre otras.

Finalmente, autores dentro de la corriente del decrecimiento como Latouche (2010), D’Alisa et al. (2014) u otros como Trainer (2017) que formulan propuestas como la Vía de la Simplicidad, se remiten a que se trataría de cambios de modelo más o menos radicales que van mucho más allá de ámbitos puramente económicos (que pudieran asociarse a mecanismos únicamente técnicos) para llegar a la necesidad de modificar aspectos culturales profundos de carácter civilizatorio. Sobre la base de que no se puede crecer de manera infinita en un planeta finito y que el crecimiento económico no aumenta el bienestar de las personas ni acaba con la pobreza ni la desigualdad, insiste en la necesidad de descolonizar la cultura del consumismo y el utilitarismo. Para ello proponen el reparto equitativo del uso de los recursos, así como la participación, revitalización y profundización democrática.

Respecto a los denominados como fenómenos relacionados con las economías transformadoras, comprendidos como: sin base social organizada ni proyecto común y que son interpretados desde diferentes posiciones políticas e ideológicas, serían casos surgidos desde el Norte global como: economías comunitarias, economías de los cuidados y curas, consumo responsable, emprendimiento social, innovación social, empresas sociales, responsabilidad social corporativa, y también la economía circular; y desde América Latina y otras zonas del Sur Global principalmente el fenómeno de la economía de la solidaridad (Razeto, 2010) o la economía social y solidaria (Coraggio, 2016) más como propuestas que como prácticas materializada aunque cuente con diversas experiencias.

Las economías comunitarias corresponden básicamente a grupos de consumo ecológico, huertos comunitarios, espacios de gestión comunitaria, redes y mercados de intercambio, monedas comunitarias, bancos de tiempos, experiencias de vivienda colectiva, grupos de crianza compartida, entre otros. Como otro fenómeno, el consumo responsable se relaciona con el consumo de productos alimenticios ecológicos y/o de comercio justo, prácticas de ahorro y eficiencia energética en el hogar y reciclaje de residuos. Asimismo, la economía de los cuidados se centra en la atención a las personas dependientes y también a las proveedoras de cuidados; se trataría de tareas asumidas históricamente por mujeres en la histórica, aunque diversa, división sexual del trabajo. Se considera que las tareas de cura son la base para la reproducción de la vida y la garantía del bienestar y, por eso, los objetivos económicos y sociales habrían de enfocarse en ellas, y relegar el trabajo mercantil a un segundo término. 
El emprendimiento social es un fenómeno sujeto a mayor ambigüedad respecto a sus interpretaciones y lecturas. Se identifican hasta 4 corrientes en su interior: la de innovación social, la de empresa social, la corriente europea y la corriente latinoamericana. Parte de gente que se mueve por motivaciones sociales y no por afán de lucro. La innovación social también cuenta con diversos enfoques articulados. Un enfoque económico y de gestión; es decir, procesos que impulsan los emprendedores sociales. Otro socio-ecológico entendido como el proceso complejo que con la introducción de nuevos productos, procesos o programas se cambian las rutinas básicas, los recursos, los flujos de autoridad y las creencias del sistema social. Sus mayores experiencias y prácticas se sitúan en: prevención de la cardiopatía coronaria, redes sociales de vecinos de soporte a la gente mayor; ecomapas urbanos para la reducción de emisiones tóxicas y bancos éticos. Las empresas sociales en esa búsqueda de equilibrio entre lo económico y lo social conjugan objetivos múltiples como su alto grado de autonomía y riesgo económico, bajo nivel de puestos remunerados, carácter participativo o el objetivo explícito de beneficiar a la comunidad (Díaz Foncea et al., 2012). Finalmente, la responsabilidad social corporativa es un fenómeno en torno a las economías transformadoras con un extenso recorrido de implementación práctica aunque aún se adopte de forma minoritaria, con diversidad de herramientas de gestión y procedimientos dedicados a medir y acompañar el proceso de fortalecimiento de este ámbito para nuevas empresas. Estos dos últimos fenómenos guardan importante relación con la economía circular que será abordada en profundidad en el siguiente apartado.

\section{Tabla 1. Movimientos y fenómenos de las Economías transformadoras en Centro y Periferia}

\begin{tabular}{|c|c|c|}
\hline & MOVIMIENTOS & FENÓMENOS \\
\hline \multirow[t]{8}{*}{ CENTRO } & Decrecimiento & Economías Comunitarias \\
\hline & Economía Colaborativa & Consumo Responsable \\
\hline & Economía del Bien Común & Economía Circular \\
\hline & Economía de los Comunes & Economía de los Cuidados \\
\hline & Economías Feministas & Emprendimiento Social \\
\hline & & Empresas sociales \\
\hline & & Innovación Social \\
\hline & & Responsabilidad Social Corporativa \\
\hline \multirow{4}{*}{$\begin{array}{l}\text { CENTRO - } \\
\text { PERIFERIA }\end{array}$} & Economía ecológica & \\
\hline & Economía Social & \\
\hline & Economía Social y Solidaria & \\
\hline & Ecofeminismo & \\
\hline \multirow[t]{3}{*}{ PERIFERIA } & Economía Solidaria o de la Solidaridad & Economía Popular \\
\hline & Economía de la vida & Economía Informal \\
\hline & Economía popular y solidaria & Ecologismo de los pobres \\
\hline
\end{tabular}

Fuente: Elaboración propia desde Suriñach (2018) y Coraggio (2016). 


\subsection{La economía circular como propuesta}

En este contexto de reconocimiento de nuevos fenómenos, movimientos, propuestas, teorías y prácticas que a su vez determinan una profusión de neoconceptos (Chaves \& Monzón, 2018), ha aflorado desde escenarios del Norte global el de economía circular como una de las denominaciones en boga. Mientras autores como Reike et al. (2018) constatan de que no se trata en absoluto de un concepto reciente sino con orígenes en el XVIII, y que desde los 60 se señala en la Unión Europea, sí es evidente su restauración en la última década especialmente desde ámbitos político-administrativos como la Unión Europea, el Estado de China, y desde ellos, intelectuales, así como desde el ámbito empresarial y las consultoras.

Diversos autores la definen principalmente como un fenómeno y no como un movimiento, con la particularidad de venir promovido por instituciones, no contar con una base social clara y moverse desde diferentes enfoques político-ideológicos (Suriñach, 2016). Asimismo se la vincula con otros neoconceptos como economía verde, economía ecológica, economía funcional, economía basada en los recursos y economía azul que se han instalado en el mundo académico y político en los últimos años ligados a la necesidad de un desarrollo económico armónico con el medio ambiente y los recursos naturales limitados; asimismo con el desarrollo sostenible como fondo (Chaves \& Monzón, 2018). Su énfasis es muy claro respecto a otros: el ámbito medioambiental en base a la reducción y reutilización de recursos ante la finitud de éstos pretendiendo cambiar su lógica con objeto de que empresas y entidades, públicas y privadas sean más armónicas con el medio ambiente (Chaves \& Monzón, 2018, p. 27). Para estos autores resulta claro que constituyen paradigmas transversales al sistema económico y por tanto al sector público, privado tradicional y de la economía social. Para ellos correspondería a un nuevo enfoque, tanto micro como macro, para enfrentarse a los desafíos sistémicos del modelo actual y que, por lo demás, resulta claramente complementario con conceptos y prácticas alternativas más instaladas como la economía social.

En base a esos énfasis generales, se insiste sin embargo en la poca claridad acerca de su teoría, así como en la diversidad de definiciones que se manejan en la literatura especializada sobre economía circular. Reike et al. (2018) evalúan que el campo de la economía circular no es una disciplina académica claramente definida con características paradigmáticas sino que es abordado por académicos arraigados en varias escuelas de pensamiento, con enfoques específicos y marcos disciplinarios diferentes; y asimismo que "se trata de un campo que no goza de aislamiento académico perfecto, sino que surgió y se desarrolló en estrecha simbiosis con la formulación de políticas, la promoción y la consultoría, donde el uso de conceptos también sirve a otros intereses como la persuasión, la reducción de la complejidad para fines de comunicación y la creación de un negocio" (p. 253).

Por otra parte, analizando definiciones en literatura especializada sobre economía circular, hasta 7 énfasis diferenciados señalan Kalmykova et al. (2018) que van desde que se trata de: (i) una economía industrial en la que los flujos de materiales continúan circulando a una alta velocidad sin ingresar a la biosfera; (ii) una economía que proporciona múltiples mecanismos de creación de valor que se desacoplan del consumo de recursos finitos y se centra en la opti- 
mización de stock; (iii) su énfasis en las actividades de reducción, reutilización y reciclaje realizadas en el proceso de producción, circulación y consumo, y la minimización de la generación de residuos; (iv) constituir una alternativa a la economía lineal tradicional; (v) un sistema económico e industrial basado en la reutilización de productos y materias primas; (vi) un modelo industrial que separa los ingresos de los insumos materiales; y finalmente, (vii) un sistema industrial restaurativo por intención y diseño donde en lugar de descartar los productos antes de que el valor se utilice por completo, deben usarse y reutilizarse (p. 194). Promotores de propuestas y prácticas como la segunda vida de los materiales, la reutilización y reciclaje, la biomimética, el consumo colaborativo, la reparación, el diseño para durar, entre otras muchas, se plantean esta propuesta económica como transformación hacia la sustentabilidad. En ese sentido se indica también la necesidad de transformación óptima de la energía, la recuperación de los residuos y el tratamiento del agua como centrales para los nuevos modelos económicos (Frérot, 2014). Desde otra perspectiva Kirchherr et al., (2018) sistematizan hasta 114 definiciones de economía circular en la literatura especializada que demuestra énfasis muy diversos y, en ocasiones, incompatibles.

Pese a la señalada diversidad de énfasis de la economía circular en diversos autores y documentos, existe mayor coincidencia respecto a cuáles son las escuelas de pensamiento que la han desarrollado. Resulta significativo como desde latitudes muy diferentes, sin citarse mutuamente y publicados el mismo año, existe pleno consenso entre Belda (2018) y Martínez \& Porcelli (2018) respecto a que: la economía del rendimiento, el diseño regenerativo, de la cuna a la cuna, la ecología industrial, la biomimética, la economía azul y el capitalismo natural, sintetizarían la totalidad de 7 escuelas en la temática. Coincidiendo entre ellas en diferente grado acerca del diagnóstico de inviabilidad del modelo lineal actual, las ideas y prácticas fuerza las encontramos sintéticamente en: la inexistencia de desechos en los ecosistemas y su capacidad constante de regeneración integral, la relevancia de reaprovechar los desechos en procesos productivos circulares, existencia de viabilidad económica para su consumación, el diseño regenerativo, la toxicidad limitada, la ecología social y cultural, la ecoeficiencia, la basura como alimento, el supraciclaje (un reciclaje mucho mayor que el infraciclaje actual), la biomímesis o innovación inspirada en la naturaleza, la ecoinnovación, la simbiosis industrial (Jaca et al. 2018), residuos 0, metabolismo industrial, avanzar hacia un modelo de negocio basado en soluciones (Belda, 2018), (Martínez \& Porcelli, 2018), la minería urbana o de vertederos (Reike et al. 2018), entre otros, algunos de los múltiples y diversos conceptos, prácticas, propuestas planteadas y/o llevadas adelante por estas escuelas.

En cuanto al ámbito de la circularidad vinculado a la economía circular, las actuaciones a implementar encuentran una orientación clave en el debate y aplicación de las denominadas como Rs. Reike et al., (2018) encuentran hasta 38 conceptos iniciados con RE en el ámbito de la literatura especializada, los cuales también apuntan a objetivos y prácticas muy diversas y en ocasiones incompatibles; ello deriva en apuestas que van desde 3 a 10 Rs en un marco, confuso sobre su ordenación, prioridad y relación. Jiménez (2020) propone una tipología de 10 de ellas que, en la medida que tienen énfasis diversos, avancen de mayor a menor circularidad. Para el objetivo de esta propuesta para economías transformadoras en países no industrializados se 
fundamentaría en las 3 Rs centrales de reducción, reutilización y reciclaje, a las cuales sumamos otras como reparación, restauración e incluso refabricación, más lejos de las realidades socioeconómicas del sur quedan otras como la remarketización o resintetización.

También resulta significativo sistematizar los campos económico-productivos en que se vienen implementando a nivel empresarial iniciativas de economía circular. Las experiencias más avanzadas, con mayor inversión de capital e investigación se sitúan en países del centro de la economía mundo (Belda, 2018), aunque también se deba reseñar algunas en campos específicos existentes en países del sur global, incluidos algunos latinoamericanos (Martínez \& Porcelli, 2018; Reike et al., 2018). Corresponde a campos que van desde el rediseño, diseño innovador, la re-fabricación, la reutilización de insumos de la cadena productiva en los más diversos ámbitos de ella. Asimismo a nivel institucional sean públicos o privados, los centros de investigación y promoción (Belda, 2018) coinciden con esa distribución norte-sur, aunque por otra parte las prácticas de recogida, reciclaje, reutilización como políticas locales se ejecutan con diferente resultado en muchas localidades del mundo.

Esa transversalidad del concepto señalada por Chaves \& Monzón (2018), la pluralidad de énfasis en su definición y esa diversa adscripción político-ideológica de sus escuelas y pensadores permiten observar tendencias incluso divergentes en sus prácticas y enunciados, situación que complejiza su definición y comprensión de su lógica de actuación. Reike et al. (2018) distinguen en su interior las que denominan como escuela reformista y transformacionista donde existirían posturas contrapuestas respecto a campos tan relevantes como: "(i) reducción absoluta de entrada de recursos, (ii) el equilibrio entre dimensiones de sostenibilidad e, incluso, (iii) la modificación del orden económico, es decir, el capitalista, la que, siendo promovidas por la segunda, la tendencia reformista descarta de pleno" (p. 250). Una pregunta básica atraviesa el debate entre ambos posicionamientos: ¿se puede reducir el uso de materiales mediante un equilibrio sustentable ambiental, social y económico sin alterar la lógica del capitalismo?

Atención especial merece el tema de la rentabilidad de este modelo de economía y las posturas frente a ella. Desde los documentos de la Unión Europea y ciertos autores se insiste en que los cambios que la economía circular exige no deben afectar el nivel de rentabilidad en la economía de mercado (Cerdá \& Khalilova, 2016). Kalmykova et al. (2018) señalan que se espera de la economía circular promueva el crecimiento económico mediante la creación de nuevos negocios y oportunidades de empleo y ahorre materiales. En otros casos aparece como una disyuntiva abierta: "La economía circular se propone convertir en una gran oportunidad de negocio el enorme desafío medioambiental que supone el modelo actual de comprar y tirar. Si se pone en marcha, exige cambios radicales en la manera de producir y consumir. ¿Va en serio o es un mero slogan publicitario?" (Trillas et al., 2019, p. 35). El anterior titular refleja con claridad el debate abierto entre reformistas y transformacionistas respecto al tema de la rentabilidad.

Otra expresión clara de esa tensión es la obsolescencia programada. Según F.-Protomastro (2013) existe debate en si ésta sería programada o respondería a un natural fin de ciclo de los productos; por ejemplo que los aparatos eléctricos o electrónicos (AEE) tarde o temprano devendrán en residuos eléctricos y electrónicos (RAEE). A. Leonard (2010) que la denomina como obsolescencia planificada, arroja luz al respecto al diferenciar cuando un producto es 
superado por otro y caería en una obsolescencia tecnológica, de cuando está programado para ello, tal cual asistimos a gran parte de los celulares, impresoras y tantos otros productos tecnológicos actuales que son desechados mucho antes de esa superación tecnológica. De hecho, la autora profundiza en que habría sido ampliamente difundida desde los años 30 en EEUU y, además, habría sido articulada con la obsolescencia percibida trabajada en ámbitos publicitarios para que los consumidores sientan el deseo de cambiar sus productos con mucha frecuencia por sentirlos pasados de moda. Esta lógica pone de manifiesto radicalmente la confrontación reformista - transformacionista. Keucheyan (2019) propone una medida aparentemente sencilla que podría modificar radicalmente el consumo hacia la sustentabilidad: exigir a los productores la ampliación significativa de las garantías de gran número de productos industriales. Modificar la obsolescencia programada atentaría directamente contra un mecanismo central de acumulación del modelo actual, pero a su vez una economía circular profunda no debería quedarse en ser la recicladora de un modelo de y en crecimiento, sino intervenir de pleno en modificar la lógica que provoca su insustentabilidad. De ahí que las propuestas más transformadoras de economía circular se vinculen directamente a una economía de la funcionalidad en que el producto sea en todo momento propiedad del fabricante, que cede el uso al cliente, y por tanto (a la inversa que en la actualidad) estará muy interesado en que funcione bien el mayor tiempo posible, así como considerará prioritario diseñarlo teniendo en cuenta su posterior reciclaje, que en última instancia le acabará surtiendo de materias primas.

Éste parece reflejar la tensión de fondo entre posturas que enfatizan la sustentabilidad de sus prácticas como motor regente, respecto a las que la observan debido a su rentabilidad como adaptable aun a la lógica capitalista más vinculada a crecimiento y con importante intervención del capital. Mientras existe ambigüedad en la literatura institucional de la Unión Europea sobre sus prácticas y límites, sus normativas orientan en mucho mayor medida el mundo empresarial que el social al respecto. Como fenómeno principalmente institucional su énfasis central está en su viabilidad como negocio por mucho que vayan proliferando prácticas sociales, comunitarias, barriales, familiares que la ponen en práctica. Los 5 principales informes de la Unión Europea al respecto lo confirman a través de un acento evidente en lo empresarial y mínima presencia de lo social (Comisión Europea, 2014; Unión Europea, 2016; Unión Europea, 2017; Comisión Europea, 2015; Comisión Europea, 2017). Lo social se advierte en ciertas prácticas ciudadanas pero no especialmente secundadas a nivel institucional. Por tanto, se impone la lógica de que el modelo actual es insustentable, pero existe una manera mucho más ecológica de optimizarlo obteniendo riqueza monetaria de él. En el trasfondo de sentido correspondería, tal cual nos recuerda Leff, a expresiones de la disputa actual entre la privatización del conocimiento y la capitalización del saber, y la de la apropiación colectiva, comunitaria de saberes (2003, p. 79).

El debate anterior nos acerca al campo de los límites señalados para su práctica. Ramos (2015) resulta categórico respecto a su inviabilidad por dos razones principales no atendidas: la primera es que el propio proceso de reciclaje de recursos implica, por un lado, una pérdida de recursos, pues éste no es posible al 100\%, así como, el gasto energético en el propio proceso de reciclado. El segundo sería no tener en cuenta la Paradoja de Jevons, que afirma que 
las mejoras en la eficiencia de uso de un recurso no suelen llevar a un menor uso de éste, sino que suelen derivar, por el contrario, en un uso mayor especialmente en términos absolutos. Corresponde a los efectos rebote, tanto directos como indirectos, que debido al aumento de consumos, impiden mejoras en base a la eficiencia tecnológica. 0 como expresa F.-Protomastro (2013) a mayor eficiencia en la producción de un bien de consumo, menor será su costo y, por ende, mayor su demanda (p. 25). Ramos (2015), identifica la economía circular con una propuesta muy cercana al desarrollo sostenible, claramente funcional a la continuidad del modelo económico dominante mediante ciertas reformas, pero que no lo cuestiona; y asimismo, aduce que está fundamentada en un claro optimismo tecnológico (p. 8) en gran medida indemostrable. Al respecto, Alcott (2015) afirma que existe una absoluta incertidumbre respecto a poder garantizar ahorros energéticos y materiales reales gracias a la eficiencia tecnológica.

Por otra parte Pauli (2015) insiste en los reiterados malos hábitos empresariales que impiden la adopción de las sabias prácticas de la naturaleza como base de una nueva economía como la circular. El maquillaje verde, la falta de compromiso empresarial en probar las pautas naturales, el guiarse sobre lo seguro del negocio destruyendo incluso iniciativas más sustentables son algunas de las trabas y límites que la economía circular encuentra. En la misma línea Martínez \& Porcelli (2018) recuerdan que a nivel planetario los niveles de reciclaje son muy bajos en términos absolutos para ser optimistas con la viabilidad de una economía menos lineal. Algo muy similar a lo que ocurre con las energías renovables: pese a lo mucho que se menciona a nivel mediático y académico de ellas, a día de hoy representan una proporción ínfima de la energía mundial utilizada que no supera el 5\% del total (Ramos, 2015).

Tal cual los límites señalados, se muestran las encrucijadas a superar para su viabilidad como una propuesta realmente alternativa a las problemáticas que enfrenta. Una primera se relaciona con el empleo; así, existen autores y promotores que se muestran optimistas respecto a que sería una economía que podría generar un importante número de puestos de trabajo. Sin embargo, otros como D'Alisa (2019) advierten que no se está poniendo el énfasis en la desigualdad que de alguna manera ya existe y, sobre todo, que ésta puede aumentar en su interior. De hecho, ya resultó significativo en términos de agudización de desigualdad como el inicio de la recogida de desechos para reciclaje en la mayoría de ciudades del mundo que pasó a manos de empresas, lo que significó quitar las formas de manutención que históricamente asumían de forma descentralizada miles de familias que perdieron ese sustento. Ya en la actualidad comprobamos como agentes centrales vinculados a prácticas circulares son sectores claramente precarios y poco reconocidos salarial, institucional y socialmente; por ejemplo una parte muy mayoritaria de las personas que se ganan la vida con el reciclaje en América Latina se hallan sin previsiones ni protecciones, así como se trata de un tipo de empleo informal claramente feminizado. Frente a ello el sector sí obtiene una riqueza en crecimiento no sujeta a mecanismos de redistribución.

Otro reto relevante pasa por las tendencias hacia la desmaterialización, descarbonización y desenergización que una economía alternativa a la actual debe asumir para ser tal. Como señala Jiménez (2020) la transición ecológica del sistema económico debe ser simultáneamente energética y de materiales y de bajo carbono. Así, para una propuesta relevante de eco- 
nomía circular, la reducción de materiales para la producción y el consumo no solo pasaría por optimizar su reutilización, tal cual el reciclaje, minería urbana y otros tipos de prácticas, sino especialmente por reducirla. Es importante aquí la paradoja para los países de la periferia. Mientras se señala la existencia de desacoplamiento de economías del norte debido a que estarían extrayendo menos recursos de sus territorios que en el pasado, este solo ha sido relativo pues, por el contrario, la economía mundial se habría materializado aún más y en ese proceso regiones como América Latina habrían recibido la mayor parte de la carga ambiental producto del aumento de las extracciones en sus territorios (Lorek; 2015). Como muestra, la UE importa seis veces más materias y recursos naturales de los que exporta (Trillas, 2019). La implementación de una economía circular, por tanto, enfrenta la desmaterialización como requisito sabiendo a su vez que ello no es probable en una economía que busca el crecimiento.

Lo anterior apunta a su vez a los límites del reciclaje. Advertidos sobre la imposibilidad de un reciclaje pleno (Ramos, 2015; Jiménez, 2020) ya que existen límites termodinámicos y económicos, y siempre quedarán residuos irreciclables, se insiste en que no se debe caer en una "obsesión por el reciclaje" que es solo el ámbito de los desechos y se debe intervenir sobre la totalidad de la cadena de producción y consumo, incluida la extracción. Se debe tratar de una propuesta integral que, junto con buscar la ecoeficiencia del modelo productivo, paralelamente debe encontrar la racionalidad y la suficiencia en el consumo y en los estilos de vida. Por tanto, como señala Jiménez (2020), sin duda se debe dar prioridad a una eficiente gestión del ciclo recursos-residuos, pero es fundamental superar las opciones simplistas y tranquilizadoras basadas en el «super-reciclado» (p.13). Aun así, ámbitos como la minería urbana o inversa (F.-Protomastro; 2015) pueden cobrar especial relevancia sobre todo en campos específicos de especial necesidad: la de los RAEE con alta cantidad de minerales y el campo de los metales raros altamente cotizados por su demanda y escasez.

La visión transformacionista de la economía circular defensora del equilibrio de sustentabilidades ecológica, social y económica, así como de la reducción significativa de entrada de materiales al sistema de producción, es la que está permitiendo a través de sus prácticas en la sociedad que esta haya comenzado a ser también un movimiento tal cual se compruebe en América Latina en experiencias en Colombia, Chile o México. De hecho, en América Latina parte de sus prácticas aparecen directamente relacionadas con la economía popular/social y solidaria en la medida que la gestión de reutilizaciones, reparaciones, remanofactura entre tantas, se abordan la mayoría de veces desde esta lógica organizativa económica de los sectores populares. En ese sentido se entronca de forma casi natural con otros movimientos de ellas como es el caso de la economía colaborativa en la medida que comparten de fondo un modelo basado en el uso y reúso de los bienes de consumo y no en su propiedad hasta el final de la vida útil. Algo similar se detecta con el movimiento decrecentista con el que comparten esa idea de la reducción de materiales y para ello la modificación de la lógica acumulativa e insustentable del modelo actual.

Por último destacar que se inscriben también en esta línea transformacionista los elementos más claramente alternativos de la práctica que en la actualidad está teniendo la economía circular. Según D’Alisa (2019) corresponde especialmente a las comunidades de economía cir- 
cular de código abierto que mediante expertos y diseñadores desde la base buscan promover la transparencia y el acceso abierto a la información, tecnologías y productos favoreciendo con ello soluciones de código abierto a los problemas ambientales y de recursos (p. 115). Cuestionando la propiedad privada del conocimiento y la información, así como los modelos de negocios asociados a ellas, constituyen la cara de la economía circular que en mejor medida puede conectar con realidades del sur como las latinoamericanas para marcar vías alternativas hacia una economía con énfasis fuerte en sustentabilidad e inclusión

\section{Una propuesta de Economía(s) Transformadora(s) desde la periferia 2.1. Conceptos fundamentales para caracterizar la propuesta}

Tras el ejercicio de evaluación genérica de la tendencia de la economía circular como práctica y propuesta en el marco de las economías transformadoras, el propósito de este apartado se centra en analizar la viabilidad de su aplicación/incorporación a la realidad estructural de las periferias como entidad y América Latina como parte de ellas. Como se analizaba en el punto 1.2 ya la propia propuesta de economía circular demuestra internamente debates y límites a aclarar respecto a su posicionamiento ante un nuevo modelo económico, a lo que por otra parte se suma que se debe contrastar con la posibilidad de encaje en la realidad institucional, sociocultural, ambiental y económica en este caso de países latinoamericanos.

En ese sentido el diagnóstico sobre la economía globalizada actual y su carácter lineal, de crecimiento indefinido y mercantil resulta tajante respecto a la amenaza que constituye por su insustentabilidad ya en un plazo corto. Ello plantea como cuestión clave el para qué de esta modificación del modelo económico generando la disyuntiva de si se plantea sólo porque se está agotando como modelo, o si porque estaría fundamentado sobre lógicas de por sí insustentables, depredadoras, desiguales e injustas que decididamente se desea revertir. Asimismo centra impostergablemente el debate sobre su posicionamiento entre el énfasis en la sustentabilidad o en la rentabilidad económica y el lucro. Dos conceptos que llegados al escenario actual aparecen como incompatibles: una apuesta por la sustentabilidad fuerte que va estrictamente asociada a la idea de cobertura de las necesidades básicas de la humanidad y la naturaleza versus un modelo que siga garantizando la acumulación en base al crecimiento por la vía de la mercantilización y financiarización, incluso aunque se pudiera llegar a lograr mejor distribución social.

Tal cual debaten reformistas y transformacionistas dentro de la economía circular (Reike et al., 2018) ciertos aspectos como: si se centra necesariamente en el crecimiento económico indefinido, si nos referimos a sustentabilidad débil o fuerte (Toledo, 2015), si interviene so- 
bre la desigualdad social y ambiental, entre otros, deben ser esclarecidos para evaluar su real viabilidad y grado de impacto sobre las problemáticas que declara querer intervenir. En ese debate, el aporte de la economía circular es claramente hacia el ámbito de la sustentabilidad medioambiental, pero sus iniciativas encabezadas desde instituciones ha resultado especialmente ambigua respecto a si ella debe quedar supeditada también a la rentabilidad y oportunidad económica que puede significar su puesta en marcha como fuente de negocios y riqueza monetaria.

La anterior dualidad guarda relaciones claras con el desfase estructural moderno entre el norte y el sur globales en la economía-mundo y la gran divergencia en crecimiento de unos y otros agudizada desde la revolución industrial. Los resultados para la periferia de esa economía mundo construida de la implementación de dicho modelo es evidente si se analiza la situación de sus mayorías y los sectores más desfavorecidos. La iniciativa de la economía circular aparece pues a nivel del norte como equivalente al centro de esa economía globalizada y especialmente apoyada por instituciones para su promoción. En ese sentido el énfasis en la sustentabilidad medioambiental de esta propuesta se inscribiría como un aporte fundamental también para los países y pueblos del sur global, pero que, solo como un componente que sin intervenciones en el ámbito socioeconómico, la hacen insuficiente e inviable para sus realidades. Los perjuicios que en términos de amenaza de su biodiversidad, contaminaciones, derrames socioambientales, desigualdad, empobrecimiento e injusticia social, entre tantos otros, ha portado el modelo lineal global es tan significativo para esa periferia que una propuesta de mejora debe apuntar necesariamente y sin ambigüedades hacia transformaciones de fondo y no un simple proceso de reforma o maquillaje verde (Pauli, 2015). En la línea de la propuesta de Leff et al. (2003), se debe apuntar a construir una nueva racionalidad productiva, basada en los potenciales ecológicos de la naturaleza y en los significados culturales de los pueblos.

\subsection{Alternativas desde la periferia y circularidad}

Resulta significativo como, junto a esas notorias brechas (tecnológica, renta per cápita, consumos per cápita, huella ecológica, entre tantos) y desigualdades estructurales (de presupuestos, coberturas de servicios básicos, niveles educativos, empleo formal, etc.) entre países del centro y la periferia, las prácticas socioeconómicas de estos últimos ofrecen oportunidades a explorar acerca de la viabilidad de alternativas al modelo económico actual. En términos históricos es evidente como el capitalismo se vincula a las periferias coloniales de una forma necesariamente diferente a como lo hace en la zona central en donde afloró y se ha desarrollado en su máxima expresión. Conceptos como capitalismo periférico (Coraggio, 2016) en directa relación con la existencia de articulaciones de modos de producción bajo la hegemonía del modelo capitalista (Quijano, 2011) pero que no existe nunca de forma exclusiva, situarían a América Latina, tal cual otros territorios que fueron colonizados, como aquellos donde coexisten con diferentes niveles de desarrollo y en escalas diversas, muy distintos modos productivos, de consumo e intercambio, así como lógicas y prácticas económicas; el capital es el eje dominante de articulación pero no el modo exclusivo. En su interior coexisten otros subsistemas 
como otras formas alternativas de producción, intercambio, consumo (economía popular y solidaria, economías étnicas, economía campesina, reciprocidad, entre otras) que no cuentan con plena autonomía y aparecen en constante interdefinición con el sistema superior que sí goza de ella. Desde una perspectiva complementaria Santos insistirá desde las que denomina como 5 ecologías en aquella de las productividades, reconociendo que junto a la lógica dominante productivista en base a una altísima inversión de energías fósiles, se deben recuperar y valorizar los sistemas alternativos existentes de producción, de las organizaciones económicas populares, de las cooperativas, de las empresas autogestionadas, de la economía solidaria, etc., que la ortodoxia productivista ocultó o descredibilizó (2009, p. 123).

Es significativo como en sociedades de la periferia existiría menor arraigo de ciertas prácticas y lógicas de ese sistema principal, a la vez que también surgirían otras ajenas a ella. La abundancia y niveles de producción y consumo alcanzados en el centro de la economía-mundo bajo el sello de la extralimitación de las últimas décadas, son, sin duda, parte de su acumulación y por ello mismo, aconteció de forma radicalmente diferente en territorios no centrales. Habiendo participado de otra manera en los procesos de modernización sin haber vivido los procesos socioculturales de la modernidad occidental, evidentemente las prácticas y relaciones con el medio, la ordenación de la cobertura de necesidades, las relaciones de intercambio o interpersonales a través del trabajo muestran expresiones diferentes en distinto grado.

En ese sentido es comprobable como los niveles de reutilización, recuperación, reparación siguen siendo prácticas habituales en muchos sectores de sus poblaciones en que esa lógica de comprar, usar y tirar no se practica en el mismo grado ni por toda la población. Como ejemplo elocuente se conoce como las poblaciones del sur están claramente por debajo de la media de carga por persona del planeta a diferencia de las del norte claramente por encima (Mosangini, 2012,210). Tal cual se analizaba, en esa estructura desigual de la economía-mundo la periferia no produce lo mismo ni al mismo volumen que el centro, como tampoco consume o desecha al mismo nivel ni de las mismas formas. El capitalismo no se manifiesta con tanta expansión en los hábitos de las mayorías de la periferia (niveles de consumo, de desecho, de gasto, de ahorro, de crédito, etc.), a la vez que la permanencia y recreación de otros sistemas productivos, de intercambio y consumo muestran también otras prácticas.

Lo anterior no se explica únicamente por esas razones estructurales de distribución de roles por zonas y países en el modelo de la economía-mundo sino también por los antecedentes socioculturales de los territorios. El ejemplo más evidente para América Latina en las últimas dos décadas ha sido el del Buen Vivir que se localizaría en el mundo andino-amazónico pero que como propuesta se intenta extrapolar a otros territorios. Como señala Marañón (2018), el Buen Vivir, surgido en América Latina se va perfilando como un nuevo horizonte histórico de sentido, ya que se orienta a tratar de rehacer la vida a partir de la solidaridad humana y con la Madre Tierra en todas las dimensiones de la existencia social: el trabajo, el género, la autoridad colectiva, la subjetividad y la "naturaleza" (p.18). Gudynas y Acosta (2011) enfatizan su relación no instrumental con la naturaleza como el elemento distintivo central del Buen Vivir, el más claramente antimoderno, ya que todas las variantes de desarrollo surgidas de la modernidad insistirán de forma central en su oposición a ella, su objetivación y su instrumentalización. 
Escobar (2019) recalca que desde el Sur Global las visiones de transición, como el Buen Vivir, tienen un carácter biocéntrico que enfatizan la interdependencia radical de todo lo que existe. Inspirado en las culturas originarias del continente, el Buen Vivir no constituiría una simple propuesta alternativa operativa sino que aportaría desde otras concepciones y cosmovisiones de la sociedad y la vida presentes en el subcontinente.

Este escenario nos sitúa ante una construcción de economías alternativas desde América Latina como periferia entendida como proceso de transición entre cuyas expresiones está la de propia economía de transición. Transición desde una economía capitalista lineal, extractivista, insustentable, crematística, generadora de injusticia y desigualdad hacia economías vinculadas a la vida en su sentido amplio: sustentable, inclusiva, subjetiva, de cuidados. En ello convergen esas concepciones históricas todavía presentes en colectivos del continente que están siendo resignificadas al contexto actual, más los múltiples aportes posteriores que hemos analizados en forma de movimientos y fenómenos de superación de las limitaciones e impactos del modelo principal. Como señala Dussel (2015) ya la economía del capital ni siquiera subsume a grandes masas trabajadoras sino que las expulsa y desde ahí mismo, sobre todo en zonas de periferia, surge la transición hacia economías otras vinculadas al sustento de la vida. Escobar (2019) acota que esas transiciones están aconteciendo mediante multiplicidad de prácticas que, a pesar de sus contradicciones y limitaciones, expresan los valores de sociedades ecológicas, no capitalistas, no patriarcales, no racistas y pluriversales (p. 460).

Las muestras de esas transiciones son múltiples en muy diversos campos, especialmente mientras más cercanos permanecen a la cobertura de necesidades básicas (Trainer, 2017;Dussel, 2015;Max-Neef, 1998), entre las que encontramos algunas vinculadas a la circularidad. El campo agropecuario es quizá el más evidente mediante prácticas como la agricultura campesina e/o indígena (Houtart, 2015; Paño, 2019) o la agroecología (Trainer, 2017), pero también se hace evidente en campos como la alimentación, el reciclaje, compostaje, intercambio de servicios, permacultura, entre tantos otros. Los niveles de circularidad son siempre superiores a aquellos de la economía lineal industrial, con considerables sinergias positivas para el reaprovechamiento, los niveles de equidad y justicia social o la disminución del impacto ambiental. Como ejemplo Villarán et al. (2017) investigan la alta potencialidad y diversidad de incorporación a la economía circular de productos de la industria hortofrutícola. Tal cual se menciona para la agricultura, diversos pueblos indígenas americanos practicaban y siguen practicando importantes niveles de conservación-circularidad con la naturaleza que, además parten de una concepción de integración a ella (Toledo, 2015) y no de instrumentalización y objetivación.

En esta línea y referido estrictamente a economía circular en el último tiempo, no faltan experiencias también a nivel del sur global. Más allá de experiencias en países como India, Sudáfrica, Ghana y muchos otros, también en América Latina se identifican algunas significativas. En el ámbito más estrictamente productivo Martínez \& Porcelli (2018) refieren a dos grandes campos de diferente grado de circularidad en empresas argentinas: el desperdicio de alimentos y las empresas B; entre estas últimas evaluaron para distinguir prácticas de marketing verde de otras con iniciativas realmente sustentables, y contabilizaron hasta 13 en muy 
diversos campos (ladrillos ecológicos, café, cerveza, vidrio, celulares reutilizados, zapatillas, poliestireno expandido, latas de aluminio 100\% reciclables). Otro campo especialmente pródigo al respecto es el del reciclaje con experiencias organizativas, productivas notables en ciudades como Buenos Aires (Grassi, 2011; Parizeau, 2011; Ruggerio, 2011; Abduca, 2011), Bogotá (Parra, 2011), Cuenca, Portoviejo (Solíz et al., 2018); o en genérico, casos de países como Colombia (Rodríguez, 2011) y Chile (Alaniz, 2015). La artesanía en torno a productos reutilizados es un campo en expansión en el subcontinente en el que entroncan la capacidad histórica de los oficios artesanales con la posibilidad y necesidad de reutilización ahora, también, de nuevos materiales.

Más allá de los campos organizados que en buenas prácticas han derivado en cooperativismo y otras modalidades de economía social, se siguen apreciando importantes niveles de reutilización a nivel doméstico cotidiano, especialmente en los sectores rurales y populares de América Latina y el sur global en general. Lejanos a prácticas que requieran altos niveles de inversión de capital, investigación, innovación tecnológica o nivel adquisitivo para consumirlos debido a no ocupar roles relevantes en la economía global en esos campos, por otra parte, persisten prácticas en amplios sectores sociales más cercanos a la circularidad que, desde hábitos cotidianos a capacidades organizativas, facilitan su presencia y profundización en procesos productivos.

\subsection{Pautas para una(s) economía(s) transformadora(s) para el sur}

Una propuesta socioeconómica y ambiental contextualizada para escenarios del sur como América Latina se debe construir desde (i) lo que se cuenta: tradiciones, recursos, prácticas acumuladas; (ii) lo que se quiere superar: extractivismos, linealidad, energías contaminantes, crecimiento superfluo, desechos insustentables, injusticia social y pobreza; y finalmente, (iii) las nuevos movimientos y fenómenos hacia economías transformadoras: lo supralocal, cooperativo, colaborativo y solidario, inspirada en la naturaleza, conservacionista de ecosistemas, que incorpora cuidados y, asimismo, reconoce la diversidad de saberes, productividades, escalas.

Como conjunto de pautas genéricas a conjugar además según territorios y potencialidades, cabe destacar la idea de diversidad que permite hablar en plural de economías transformadoras para los territorios más que de un solo modelo. Sus énfasis en lo universal, lo holístico de comprender una realidad integrada, de sustentabilidad fuerte social y ecológica, con las necesidades básicas humanas y naturales como motor de la actividad, componen esta propuesta vista como sistema integrado dinámico y en constante interacción. Los principios normativos que fundamentan son los que se plantean a continuación. 


\section{Cobertura de necesidades humanas básicas}

Conscientes acerca del por qué móviles centrales de la economía actual como el crecimiento económico indefinido y la búsqueda de rentabilidad son elementos causantes de la crisis del modelo y su sustentabilidad, la centralidad debe pasar a la cobertura de las necesidades básicas de la totalidad de personas y de la naturaleza en pleno. Este fundamento se hace aún más evidente con el análisis entre territorios del centro y la periferia, teniendo en cuenta las brechas en aumento entre uno y otro.

Desde hace algunas décadas existe una literatura relevante propia de América Latina sobre el tema. Max-Neef, Elizalde \& Hopenhayn (1998) señalan la existencia limitada de necesidades básicas para todos los pueblos y personas, en los distintos tiempos históricos que serían las de: subsistencia, protección, afecto, entendimiento, participación, ocio, creación, identidad y libertad. Su definición como atributos esenciales finitos, pocos y clasificables relacionados con la evolución humana, mostrarían una tensión constante y dialéctica entre carencia y potencia respecto a ellas. Lo que sí variaría ostensiblemente son las formas de cubrir esas necesidades señalando para ello las categorías de satisfactores, entendidos como las formas de Ser (atributos personales o colectivos), Estar (espacios, ambientes), Hacer (acciones) y Tener (relacionadas con estructuras humanas: instituciones, normas, mecanismos, leyes, herramientas). Ordenan los satisfactores en 5 tipos según sean más o menos óptimos para esa cobertura de necesidades básicas como: sinérgicos: atienden a varias necesidades; singulares: solo atienden a una necesidad; Inhibidores: respecto a otras necesidades; pseudo-satisfactores: fuerte arraigo en la tradición pero baja cobertura de necesidades; y finalmente, violadores o destructores. En nociones similares de necesidades básicas insisten autores como Trainer (2017) o Chaves \& Monzón (2018). Asimismo Dussel $(2015,20)$ lo vincula con que el cumplimiento de esas necesidades básicas constituyen además las exigencias éticas o normativas fundamentales de los sistemas económicos que toman con seriedad la materialidad de la subjetividad de la corporalidad humana.

Desde la visión de la periferia y América Latina en particular, una(s) economía(s) que resulte(n) trasformadora(s) y aporte(n) abiertamente a la cobertura de las necesidades pasa por este enfoque trabajando abiertamente por la eliminación de pseudo-satisfactores, o satisfactores inhibidores o destructores. Las transiciones necesarias son múltiples en ese sentido, pero teniendo en cuenta que la mayoría de la población trata de dar cobertura a ese tipo de necesidades, el gran reto es orientar las políticas institucionales y prácticas sociales hacia ellas en detrimento de los tipos de satisfactores dominantes en la actualidad.

\section{Sustentabilidad fuerte}

De la mano del amplio debate en las décadas pasadas acerca del desarrollo sostenible/sustentable quedaron en evidencia las tendencias internas existentes respecto a la sustentabilidad como concepto clave. Parte de ese debate ante estas alternativas era aquel sobre su adaptación a los modelos dominantes o si plantean posturas radicales que exigirían transformaciones claves en su interior (tratamiento de la naturaleza, abandono de niveles de crecimiento, supe- 
ración de economicismos, entre tantos). En ese sentido el concepto de sustentabilidad fuerte (Toledo, 2015) como aquella no puramente ecológica sino social y ecológica, constituiría la base de esta propuesta.

Mauerhofer (2008) ya había señalado la idea de la sustentabilidad apoyada en lo natural, social y económico en ningún caso como bases idénticas ni similares. Deja claro que los capitales natural y social son, por lo tanto, precondiciones para el capital económico donde el natural es el marco fundamental donde se alojan los otros dos y por tanto, la sustentabilidad tiene su clave en un equilibrio entre ellos con los sistemas naturales como centrales. Ampliamente trabajada por la ecología política con expresiones fuertes en América Latina (Leff,2014), Leff et al. (2003), Svampa (2018), Escobar (2007), Alimonda (2011) o Alimonda et al., (2017) plantean que en ningún caso otros móviles o intereses deben intervenir sobre la necesidad de sustentabilidad permanente de los distintos ecosistemas y la totalidad de grupos humanos para todos sus miembros. En este campo se inscribe la denominada como bioeconomía circular (Jiménez, 2020) centrada los ámbitos alimentarios y ecológicos de la economía.

\section{Reducción relevante de extractivismos}

Resulta significativo poner entre estas pautas propositivas una con el énfasis en lo que no se debe hacer. Sin embargo, el impacto de estas prácticas para las sociedades y ecosistemas del sur es tan significativa que debe aparecer como una cláusula explícita. Construir economías transformadoras para sus sociedades se debe central ineludiblemente en reducir ese modo especialmente depredador, generador de desigualdades y con múltiples derrames en la población y medioambiente que constituyen los extractivismos mineros, agroindustriales, forestales y pesqueros. Ellos resultan destructores tanto de los medios en que ampliamente interviene como del conocimiento y sabiduría acumulada de sus habitantes históricamente instalados en los territorios. Superando un planteamiento dual, la propuesta de superar la economía relacionada con los extractivismos para apostar por una de la vida que no atente contra la reproducción de las poblaciones y garantice la sustentabilidad de los ecosistemas y culturas, constituye otra pauta central.

\section{Circularidad de recursos}

Tal cual la inspiración en la naturaleza, este es otro elemento clave que se recoge de la economía circular para la propuesta de economías transformadoras del sur. La amplia literatura revisada, nos acerca al enfoque transformacionista de ella en que sin duda, reducir y recuperar elementos considerados como desechos en la economía lineal se convierte en central. Ello entronca con relativa facilidad con prácticas extendidas de reutilización, reaprovechamiento o actualmente reciclaje de materiales que sectores sociales, especialmente populares, han practicado históricamente en el Sur Global. Incidir sobre la reducción de la linealidad (eliminando usos desechables, energías contaminantes, entre tantos) para promover la recuperación pero siempre desde lógicas de decrecimiento de las producciones y consumos superfluos, así como 
de sustentabilidad fuerte resultan un aporte fundamental. En clara vinculación con uno de los puntos anteriores Jiménez (2020) propone al respecto el concepto de circularidad sostenible.

Así como debe operar directamente sobre una disminución de la extracción, los desechos se convierten en el punto donde interrumpir la lógica lineal para, mediante identificar su verdadero valor tanto de uso como de cambio, sea devuelta a la economía amortiguando significativamente su impacto medioambiental; ello reconociendo a la vez su valor social y económico mediante el empleo y la riqueza que genera. Su aplicación a campos como la minería urbana, el reciclaje, también en campos agropecuarios e industriales, marcarían la transición hacia su adopción.

\section{Economía popular/social y solidaria}

Definida como un subsistema al interior de la economía dominante entendida como sistema, la economía popular constituye para sociedades del sur global una práctica muy extendida que desde una inmensa heterogeneidad de expresiones permite el sustento de amplios sectores populares (Giraldo, 2017). Sin lógica autónoma plena, se observan en ella otras lógicas que no son las del sistema: la acumulación indefinida no es su móvil sino la cobertura suficiente de necesidades básicas (Coraggio, 2016). Ante ella como práctica extendida en sociedades del sur se suman propuestas superadoras que conservando su base pretenden mejoras en ciertos ámbitos organizativos, políticos, ecológicos, etc. y que corresponden a la denominada como economía social y solidaria (Coraggio, 2016) ya con prácticas en expansión en múltiples campos y territorios.

Ser prácticas ya arraigadas en sus territorios y culturas, y constituir la alternativa de cobertura de necesidades de un número muy relevante de la población latinoamericana, la convierten en fuente relevante en la que inspirar parte de las transiciones hacia economías transformadoras.

\section{Democracia socioeconómica y ecológica}

En la medida que nos referimos a procesos integrados en que la economía no está fuera de la sociedad ni rige su funcionamiento desde una lógica particular tal cual en el modelo actual, el ámbito sociopolítico en un sentido ampliado cobra una centralidad imprescindible. En los muchos casos de por ejemplo el cooperativismo a lo largo del mundo en la historia de los dos últimos dos siglos, aparece con fuerza la idea del gobierno democrático muchas veces de democracia directa y/o participativa (Santos \& Rodríguez, 2011). Desde ella para la gestión interna se rebasa con claridad la idea de democracia liberal de bajo perfil (Brugué, 2009) para ampliarlo a campos como también la democracia económica (Comín Oliveres y Gervasoni Vila, 2009). Este aspecto se relaciona directamente con otra de las pautas que es aquella de lo pre-distributivo que un sistema democrático participativo económico y ecológico garantizaría.

En términos similares se viene debatiendo sobre justicia ambiental especialmente en términos de norte-sur (impuestos ambientales por conservación de ecosistemas claves para el 
planeta, etc.). Así, la referencia a democracia ambiental ecológica (Manzini \& Bigues, 2000) incide tanto sobre priorizar el cuidado del medioambiente en directa relación con la sustentabilidad fuerte, como que existan equilibrios territoriales, ambos en términos internacionales, nacionales como regionales.

\section{Carácter inclusivo, pre-distributivo y equitativo}

Tal cual la sustentabilidad fuerte, estos énfasis socioeconómicos que pretenden incidir sobre la existencia de justicia social y disminución sustantiva de desigualdades constituyen fundamentos igualmente claves. Precisamente el fuerte arraigo histórico de la desigualdad e injusticia social en sociedades del sur estrictamente asociados a su pasado colonial marca que las alternativas transformadoras deban abordar estas temáticas de forma central.

El componente de género es un eje transversal para la comprensión de las economías del sur, especialmente aquellas vinculadas al sustento de las mayorías sociales. Resulta fácilmente constatable a través de la gran cantidad de mujeres implicadas en prácticas económicas populares/sociales que además entroncan con las economías feministas y la de curas y cuidados. Es uno de los campos en que se debe abordar en profundidad la inclusividad que necesariamente estas propuestas deben recoger para constituirse como alternativas realmente entroncadas a la realidad del sur.

Lo equitativo como demanda y búsqueda histórica aparece en propuestas alternativas como el cooperativismo y en la actualidad es plenamente articulable con la idea de pre-distribución (Subirats, 2018) como mecanismos desde las políticas públicas que, sin llegar a tener que re-distribuir a posteriori, ya incidan desde el principio en procurar distribuciones equitativas de recursos y oportunidades.

\section{Inspiración en la naturaleza, comunidades ancestrales y sus productividades otras}

La riqueza en biodiversidad de América Latina contrasta abiertamente con la pobreza de las soluciones tecnológicas aplicadas para la producción, diseño, organización en general por el sistema productivo y su carácter lineal y depredador. Pauli (2015) desde la economía azul o la biomímesis (Riechmann, 2007) dan claves fundamentales en que los diversos sistemas naturales latinoamericanos podrían dar múltiples respuestas más sustentables y justas a la hora de organizar nuevas economías.

Sirva de ejemplo el caso de países como Ecuador desde donde se escribe esta propuesta. Se trata de un país calificado como megadiverso que se puede aplicar tanto en términos de biodiversidad como de riqueza étnico-cultural que, además se retroalimentan. Parece evidente como esa riqueza en flora y fauna a la vez que abundancia en agua junto a la heterogeneidad y multiplicidad de expresiones culturales y conocimientos sobre la naturaleza y territorios constituyen una gran potencialidad en la que orientar hacia una optimización de las prácticas socioeconómicas. La biomímesis propuesta desde escuelas vinculadas a la economía circular 
históricamente ha encontrado ejemplos magníficos de circularidad y optimización de recursos no destructivos del medioambiente ni de comunidades y/o culturas; existen numerosos ejemplos hasta el día de hoy de la optimización de la gestión de recursos naturales de los pueblos indígenas, entre ellos los del propio Ecuador con el Buen Vivir como referente.

Para el sur global y América Latina aparece con claridad la necesidad de aplicarla no en campos que exigen muy alta inversión, investigación y tecnología sofisticada, ya que su papel histórico no es relevante en esos campos, pero sí en campos productivos de necesidades básicas (alimentos, energías renovables, reutilizaciones orgánicas y no orgánicas, materiales construcción, entre otros).

Estas prácticas tienen traducciones diversas a través de casos como las economías o agricultura campesinas, las de distintos pueblos indígenas todavía vigentes en ciertos territorios, cooperativas, asociaciones especialmente en ámbitos locales. Por lo demás en una búsqueda de ecología de productividades tal cual propone Santos (2009), inspirarse en la naturaleza y las otras nacionalidades históricamente no reconocidas, permite reconocer también los distintos tipos de productividades no necesariamente acumulativas ni altamente consumidoras de energías fósiles.

\section{Fortalecimiento de economía interna y local vinculada a escalas mayores}

Otra de las conclusiones claras del funcionamiento actual de la economía globalizada está precisamente en la centralización en territorios y desigualdad entre estos. Ese reparto desigual entre ellos marca en gran medida, especialmente a nivel de las coberturas básicas a los territorios rurales, una orientación prioritaria hacia el mercado internacional que como lógica habitual posterga coberturas locales. Por el contrario, la propuesta de transformación de los sistemas socioeconómicos para el sur exige invertir esa lógica también en términos formales por mucho que en términos reales sea evidente que lo global y central siempre se abastece de lo local.

Descender al nivel de la cobertura de necesidades lleva a escenarios donde las diferentes comunidades deben asumir en mayor parte esas tareas. Ello se traduce en términos de autonomía, de producción de artículos y servicios necesarios (eludiendo los superfluos no satisfactores reales), entre las cuales cobran peso también las autoproducciones (familiares, grupales), así como otras como la soberanía, poniendo especial énfasis en la alimentaria pero también energética, educativa, sanitaria y otras de las distintas localidades.

Claramente el ámbito local no puede cubrir todas las necesidades mediante producción y/o gestión propia y por ello debe existir articulación con núcleos, principalmente industriales más amplios en lo que constituye una articulación a escalas (Trainer, 2017), pero en que el énfasis se debe poner en lo local y no a la inversa. Ello requiere un descenso de consumos y el abandono de la lógica consumista no basada en necesidades, y donde la producción se va en gran medida al marco local en que se consume lo disponible disminuyendo muy sensiblemente los grandes costes energéticos de traslado global. Fortalecer en ese sentido los mercados loca- 
les, rescatándolo como institución central de intercambios incluida la reciprocidad, y lejana de la lógica mercantil del valor de cambio, es parte de la estrategia.

\section{Empleo útil, digno, colaborativo y universal}

Ante la evidencia de que el trabajo constituye un elemento imprescindible del ámbito socioeconómico, una propuesta superadora a la actual para las realidades del sur debe intervenir necesariamente sobre este ámbito. Más allá de abordar la dualidad trabajo/empleo donde solo el último es remunerado y no el genérico cotidiano de todos los actores sociales, la propuesta pone énfasis en su carácter universal (para todas y todos), su carácter de dignidad en el sentido de ser realizado voluntariamente y bajo condiciones sujetas a derechos humanos, así como se debate también sobre la utilidad de éste. El tema de la remuneración del trabajo doméstico (Federici, 2019) y de curas y cuidados sería un tema fundamental a revisar en la medida que gran parte del modelo económico actual se edifica sobre el no reconocimiento de aquel que, sin embargo, ha sido absolutamente imprescindible para su funcionamiento. Avanzar hacia una reorganización menos aislada, más cooperativa y socializada del trabajo doméstico y de cuidados, es una primera clave en este campo.

Respecto a la utilidad, en un diagnóstico sobre el modelo actual Trainer (2017) considera compleja la transición del empleo hacia un nuevo escenario precisamente por la cantidad significativa de remunerados que no estarían vinculados a la cobertura de necesidades básicas, sino a la lógica dominante del mercado asociado al crecimiento de satisfactores negativos (publicidad, marketing, ciertas industrias culturales, industrias como la armamentística, especulación, servicios financieros o tantos otros). A un diagnóstico relacionado llega Graeber (2018) en su análisis sobre la proliferación de trabajos innecesarios, perniciosos y carentes de sentido (bullshit jobs); serían diferentes a los denominados como trabajos basura (shit jobs) que, aunque ingratos y/o desagradables, son trabajos útiles y necesarios. Aun así, los primeros están habitualmente mucho mejor remunerados que los segundos. El ejemplo del campesinado especialmente en países periféricos constituye quizá su máxima expresión pese a tratarse de trabajos absolutamente indispensables para la totalidad de la sociedad; entroncaría con el concepto histórico de extorsión del trabajo campesino sobre el que se fundamentaría la acumulación y desigualdad social principal.

La conexión y articulación entre estas pautas para unas economías transformadoras para el sur se hace evidente como sinergia hacia una nueva lógica. El tema del trabajo a ser planteado en términos de cobertura de necesidades se vincula a prácticas de la economía social y solidaria, del cooperativismo a la vez que se fija en organizaciones tradicionales y otras nuevas en las que se innova al respecto. Así mismo, la economía colaborativa y la feminista también hacen aportes claves para una comprensión ampliada del trabajo.

Así, se sintetizarían gráficamente las pautas señaladas. 


\section{Gráfico 1. Pautas para economías transformadoras del Sur}

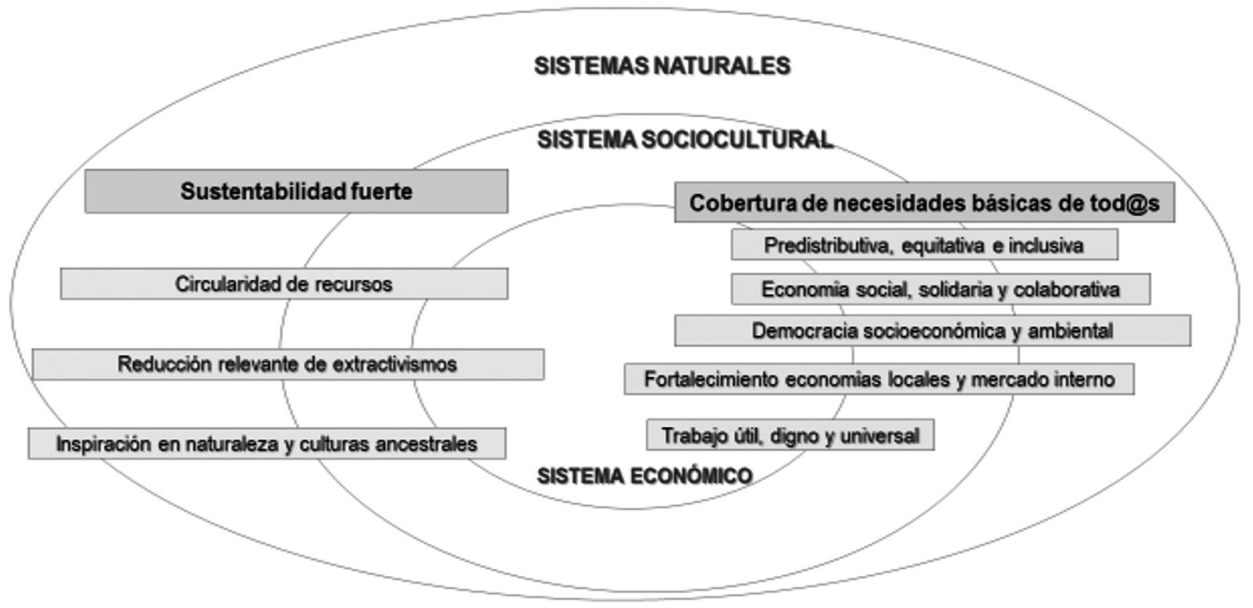

Fuente: Elaboración propia desde la división de Mauerhofer, V. (2008).

\section{Conclusiones}

- La insustentabilidad, desigualdad e injusticia social como características intrínsecas del modelo económico predominante marcado por su linealidad, mercantilización, finalidad en el crecimiento monetario se hacen crecientemente evidentes en la actualidad ante fenómenos cada vez más acuciantes de cambio climático, declive de energías fósiles, conflictos socioambientales, concentración de la riqueza y agudización de desigualdades y extractivismos de materias primas en agotamiento.

- En ese marco planetario las naciones del sur entre ellas las latinoamericanas aparecen especialmente vinculadas con ser los territorios preferentes de extractivismos, no producción de artículos industriales ni tecnológicos de alta sofisticación, menor consumo pero en expansión, desventaja estructural en el intercambio internacional, así como un bajo procesamiento de residuos. Este marco determina que las estrategias para acercarse a la construcción/aplicación de alternativas deben implicar una adaptación y contextualización fundamental a las realidades socioculturales, político-económicas, así como geoestratégicas de los países periféricos del sur al interior de la economía globalizada actual.

- Ante el cuestionamiento de la linealidad del modelo de extraer, usar, tirar y desechar existente, tanto en el norte como en el sur, se asiste a un auge de alternativas denominadas genéricamente como economías transformadoras que, divididas como movimientos cuando gozan de una base social y una propuesta de incidir en la esfera pública, o como 
fenómenos cuando no es así y son abordados desde diferentes posturas ideológicas, plantean propuestas diversas en todos los casos con la meta de ser más sustentables e inclusivas.

- La economía circular como una de las propuestas de economías transformadoras constituye un fenómeno surgido en el norte con importante apoyo institucional para su promoción, investigación e inversión que ya cuenta con experiencias significativas a nivel empresarial, aunque también encuentra algunas expresiones a nivel ciudadano. Su expansión como propuesta recoge en la última década también aplicaciones en países del sur, entre ellos de América Latina.

- En la literatura acerca de su definición y aplicación encontramos un debate primordial entre sectores reformistas y transformacionistas respecto a elementos como el nivel de entrada de recursos al sistema, el nivel de aplicación de la sustentabilidad socioambiental o su relación con la lógica capitalista. Así mismo se señalan advertencias y límites a esta propuesta respecto a elementos como que no necesariamente su práctica garantice reducciones ni optimizaciones de consumo energético o de materiales, la baja predisposición empresarial a aplicarlo sin unas ganancias monetarias evidentes, las incógnitas sobre el empleo, la obsolescencia programada o su aporte a la desmaterialización y descarbonización necesarias para alcanzar un modelo viable.

- Recogiendo la tendencia transformacionista, la economía circular está ampliando su impacto social hacia constituirse como un movimiento, así como su potencialidad transformadora, especialmente mediante la conformación de comunidades abiertas de economía circular que promueven la transparencia y el acceso abierto a la información, tecnologías y productos aportando decididamente a soluciones de código abierto a los problemas ambientales y de recursos. Desde sus aportes la viabilidad de la economía circular en países del sur podría encontrar claras alternativas a las problemáticas estructurales que impiden su desarrollo.

- Para territorios y pueblos del sur dicho elemento ya cuenta con algunas prácticas importantes y arraigadas (mayores índices de reutilización, reparación, además de por sí el menor consumo equivalente a reducción), así como otras como el reciclaje urbano o a nivel agropecuario que sustenta a muchas personas a través de economía popular y en algunos casos, incluso, social y solidaria.

- En base al contexto actual la búsqueda de lineamientos orientadores para implementar economía(s) transformadora(s) en países del sur como los latinoamericanos recoge diversos elementos ya existentes en sus territorios que combinados con otros nuevos, tanto de generación local como externa, permiten plantear una propuesta integral. Entre las pautas hacia economías transformadoras en el sur la circularidad de recursos y energías asociada a sustentabilidad fuerte y cobertura de necesidades básicas cobran especial relevancia. Es significativo como ello entronca con concepciones latinoamericanas como el Buen Vivir que lejanas a la lógica racionalista productivista abren alternativas sobre aspectos como el equilibrio con la naturaleza y la justicia social. 
- Las múltiples iniciativas existentes en este ámbito de economías transformadoras van en crecimiento en esos territorios del sur en lo que se puede identificar como economías en transición hacia modelos más sustentables, inclusivos, de cuidados, basados en utilidad común y dignidad y que, además, reflejan la conformación de visiones vinculadas al pluriverso como visión plural y diversa de las alternativas que las sociedades construyen hacia una satisfacción creativas y comunitaria de sus necesidades básicas que supere las amenazas del modelo actual.

\section{Bibliografía}

ABDUCA, R. (2011): "Acariciando lo áspero. El itinerario cartonero como construcción de un territorio", En: Suárez, F.M. \& Schamber, P.J. (Comps.), Recicloscopio II: Miradas sobre recuperadores, políticas públicas y subjetividades en América Latina, 183-222. Universidad Nacional de General Sarmiento, Buenos Aires.

ALANIZ, Á. (2015): "Recicladores de base de Chile. Contexto y perspectiva futuras", En: Suárez, F.M. \& Schamber, P.J. (Comps.), Recicloscopio IV. Miradas sobre dinámicas de gestión de residuos y organización de recuperadores, 323-337. Ediciones UNGS, Buenos Aires.

ALCOTT, B. (2015): “Paradoja de Jevons (efecto rebote)”, En: d'Alisa, G., Demaria, F. \& Kallis, G. (Eds.), Decrecimiento. Vocabulario para una nueva era, 197-201. Icaria Editorial, Barcelona.

ALIMONDA, H. (2011): "La colonialidad de la naturaleza, una aproximación a la ecología política latinoamericana”, En: Alimonda, H. (Coord.), La Naturaleza Colonizada. Ecología política y minería en América Latina, 21-60, Ediciones CICCUS, Buenos Aires.

ALIMONDA, H., TORO PÉREZ, C. \& MARTíN, F. (Coord.). (2017): Ecología política latinoamericana. Pensamiento crítico, diferencia latinoamericana y rearticulación epistémica, Ediciones CICCUS, Buenos Aires.

D`ALISA, G. (2019): "Economía circular", En: Kothari, A., Salleh, A., Escobar, A., Demaria, F. \& Acosta, A. (Coords.), Pluriverso. Un diccionario del posdesarrollo, 113-116. Icaria Editorial, Barcelona.

D'ALISA, G., DEMARIA, F. \& KALLIS, G. (2014): Decrecimiento, Un vocabulario para una nueva era, Icaria Editorial, Barcelona.

BELDA, I. (2018): Economía Circular. Un nuevo modelo de producción y consumo sostenible, Editorial Tébar Flores, Madrid. 
BRUGUÉ, J. (2009): “Calidad democrática: de la debilidad liberal a la fuerza deliberativa”, En: Parés i Franzi, M. (Coord.), Participación y calidad democrática. Evaluando las nuevas formas de democracia participativa, 121-138. Editorial Ariel, Barcelona.

CERANTOLA, N. (13 de marzo, 2019): ¿Cómo pueden las ciudades hacer la transición para ser ciudades circulares? [Presentación], Por una economía circular y competitiva $2^{\underline{a}}$ jornada de debate y experiencia, Ecologing, Barcelona.

CERDÁ, E. \& KHALILOVA, A. (2016): “Economía circular”, Economía Industrial. Empresa, Medio Ambiente y Competitividad, 401, 11-20, Ministerio de Industria, Comercio y Turismo, España.

CHAVES ÁVILA, R. \& MONZÓN CAMPOS, J.L. (2018): “La economía social ante los paradigmas económicos emergentes: innovación social, economía colaborativa, economía circular, responsabilidad social empresarial, economía del bien común, empresa social y economía solidaria", CIRIEC-España, Revista de Economía Pública, Social y Cooperativa, 93, 5-50, D0I: 10.7203/CIRIEC-E.93.12901.

COMÍN OLIVERES, A. \& GERVASONI VILA, L. (Coords.) (2009): Democràcia econòmica. Vers una alternativa al capitalisme, Projecte Democràcia Económica, Barcelona.

COMISIÓN EUROPEA, (2014): "Hacia una economía circular: un programa de cero residuos para Europa", Comunicación de la Comisión al Parlamento Europeo, al Consejo, al Comité Económico y Social Europeo y al Comité de las Regiones, Bruselas, 2.7.2014.

COMISIÓN EUROPEA, (2015): “Cerrar el círculo: un plan de acción de la UE para la economía circular", Comunicación de la Comisión al Parlamento Europeo, al Consejo, al Comité Económico y Social Europeo y al Comité de las Regiones, Bruselas, 2.12.2015.

COMISIÓN EUROPEA, (2017): "Sobre la aplicación del plan de acción para la economía circular", Informe de la Comisión al Parlamento Europeo, al Consejo, al Comité Económico y Social Europeo y al Comité de las Regiones, Bruselas, 26.1.2017.

CORAGGIO, J.L. (2014): “Otra política, otra economía, otras izquierdas", En: CORAGGIO, J.L. \& LAVILLE, J.L. (Orgs.), Reinventar la izquierda en el siglo XXI - Hacia un diálogo Norte-Sur, 35-84. Universidad Nacional de General Sarmiento, Los Polvorines.

http://www.socioeco.org/bdf_fiche-publication-1264_es.html

CORAGGIO, J.L. (2016): “La economía social y solidaria (ESS): niveles y alcances de acción de sus actores. El papel de las universidades", En: Puig Lizarraga, C. (Coord.), Economía social y solidaria: conceptos, prácticas y políticas públicas, 15-40. Hegoa, Bilbao. https://publicaciones.hegoa.ehu.eus/es/publications/351 
DÍAZ, M., MARCUELLO, C. \& MARCUELLO, Ch. (2012): “Empresas sociales y evaluación del impacto social”, CIRIEC-España, Revista de Economía Pública, Social y Cooperativa, 75, 179-198. http://www.redalyc.org/articulo.oa?id=17425798010.

DUSSEL, E. (2015): 16 tesis de economía política, Siglo XXI Editores, México.

ESCOBAR, A. (2007): La invención del Tercer Mundo. Construcción y deconstrucción del desarrollo, Fundación Editorial el perro y la rana, Caracas.

ESCOBAR, A. (2019): "Transiciones civilizatorias", En: Kothari, A., Salleh, A., Escobar, A., Demaria, F. \& Acosta, A. (Coords.), Pluriverso. Un diccionario del posdesarrollo, 458-461, Icaria Editorial, Barcelona.

FEDERICI, S. (2019): "Salarios para el trabajo doméstico", En: Kothari, A., Salleh, A., Escobar, A., Demaria, F. \& Acosta, A. (Coords.), Pluriverso. Un diccionario del posdesarrollo, 424-427, Icaria Editorial, Barcelona.

FERNÁNDEZ PROTOMASTRO, G. (2013): Minería Urbana y la Gestión de los Residuos Electrónicos, Grupo Uno, Buenos Aires. https://mineriaurbana.org/libro-mineria-urbana/.

FRÉROT, A. (3 de noviembre, 2014): “Economía circular y eficacia en el uso de los recursos: un motor de crecimiento económico para Europa", Cuestiones Europeas, 331, 1-10, Fundación Robert Schuman. Recuperado el 22 de enero de 2020 de:

https://www.robert-schuman.eu/es/cuestiones-europeas/0331-economia-circular-y-eficacia-en-el-empleo-de-los-recursos-un-motor-de-crecimiento-economico-para

GIRALDO, C. (2017): Economía popular desde abajo, desde abajo, Bogotá.

GRAEBER, D. (2018): Trabajos de mierda. Una teoría, Editorial Ariel, Barcelona.

GRASSI, L. (2011): “Inserción de los Recuperadores Urbanos en el ámbito de la ley № 1854 y su Decreto reglamentario №369/07 de la ciudad de Buenos Aires”, En: Suárez, F.M. \& Schamber, P.J. (Comps.), Recicloscopio II. Miradas sobre recuperadores, políticas públicas y subjetividades en América Latina, 55-74. Universidad Nacional de General Sarmiento, Buenos Aires.

GUDYNAS, E. \& ACOSTA, A. (2011): "La renovación de la crítica al desarrollo y el buen vivir como alternativa", Utopía y Praxis Latinoamericana. Revista Internacional de Filosofía Iberoamericana y Teoría Social, 16(53), 71-83. http://www.redalyc.org/articulo.oa?id=27919220007

HINKELAMMERT, F.J. \& MORA JIMÉNEZ, H. (2014): Hacia una economía para la vida, Editorial Tecnológica de Costa rica, Cartago.

HOUTART, F. (2015): El bien común de la humanidad, Instituto de Altos Estudios Nacionales (IAEN), Quito. 
JACA GARCÍA, M.C., ORMAZÁBAL GOENAGA, M., PRIETO SANDOVAL, V., SANTOS GARCÍA, J. \& VILES DIEZ, E. (2018): Economía circular, guía para PYMES, Ediciones Universidad de Navarra (EUNSA), Pamplona.

JIMÉNEZ HERRERO, L.M. (2020): "Economía Circular-Espiral. Opciones estratégicas desde el reciclaje al cambio sistémico", Dossieres EsF, 37, 7-15. Economistas sin Fronteras, Madrid. https://ecosfron.org/portfolio/dossieres-esf-n-o-37-la-economia-circular-una-opcion-inteligente/

KALMYKOVA, Y., SADAGOPAN, M. \& ROSADO, L. (2018): “Circular economy - From review of theories and practices to development of implementation tools", Resources, Conservation and Recycling, 135, 190-201, DOI: 10.1016/j.resconrec.2017.10.034

KEUCHEYAN, R. (septiembre 2019): “De la pacotilla a las cosas que duran” [Artículo en línea], Le Monde diplomatique. Recuperado el 20 de enero de 2020 de https://www.lemondediplomatique.cl/2019/09/de-la-pacotilla-a-las-cosas-que-duran.html

KIRCHHERR, J., PISCICELLI, L., BOUR, R., KOSTENSE-SMIT, E., MULLER, J., HUIBRECHTSE-TRUIJENS, A. \& HEKKERT, M. (2018): "Barriers to the Circular Economy: Evidence From the European Union (EU)", Ecological Economics, 150, 264-272, DOI: 10.1016/j.ecolecon.2018.04.028

KLEIN, N. (2015): Esto lo cambia todo: el capitalismo contra el clima, Ediciones Paidós, Barcelona.

LATOUCHE, S. (2010): Salir de la sociedad de consumo. Voces y vías del decrecimiento, Editorial Octaedro, Barcelona.

LAVAL, C. \& DARDOT, P. (2014): Común. Ensayo sobre la revolución en el siglo XXI, Editorial Gedisa, Barcelona.

LEFF, E. (2014): La apuesta por la vida: Imaginación sociológica e imaginarios sociales en los territorios ambientales del sur, Siglo XXI Editores, México.

LEFF, E., ARGUETA, A. \& BOEGE, E. (2003): “Más allá del desarrollo sostenible. La construcción de una racionalidad ambiental para la sustentabilidad: Una visión desde América Latina", Medio ambiente y urbanización, 1(59), 65-108. D0I: 10.1630/0326785041834793.

LEONARD, A. (2010): La historia de las cosas. De cómo nuestra obsesión por las cosas está destruyendo el planeta, nuestras comunidades y nuestra salud. Y una visión del cambio, Fondo de Cultura Económica, Buenos Aires.

LOREK, S. (2015): “Desmaterialización”, En: D’Alisa, G., Demaria, F. \& Kallis, G. (Eds.), Decrecimiento. Vocabulario para una nueva era, 144-148. Icaria Editorial, Barcelona. 
MANZINI, E. \& BIGUES, I. (2000): Ecología y democracia: de la injusticia ecológica a la democracia ambiental, Icaria Editorial, España.

MARAÑÓN, B. (2016): “De la crisis estructural del patrón de poder mundial, colonial, moderno y capitalista hacia la solidaridad económica y los buenos vivires en América Latina", Cooperativismo \& Desarrollo, 109(24), 9-26, D0I: 10.16925/co.v24i109.1500

MARTíNEZ, A. \& PORCELLI, A. (2018): "Estudio sobre la economía circular como una alternativa sustentable frente al ocaso de la economía tradicional", Lex - Revista de la Facultad de Derecho Ciencia Política de la Universidad Alas Peruanas, 22(16), 301-334, D0I: 10.21503/lex. v16i22.1659

MARTÍNEZ ALIER, J. \& ROCA JUSMET, J. (2016): Economía ecología y política ambiental, Fondo de Cultura Económica, México.

MAUERHOFER, V. (2008): "3-D Sustainability: An approach for priority setting in situation of conflicting interests towards a Sustainable Development", Ecological Economics, 64(3), 496506, DOI: 10.1016/j.ecolecon.2007.09.011

MAX-NEEF, M.A. (1998): Desarrollo a escala humana, Editorial Nordan-Comunidad, Montevideo. https://www.max-neef.cl/

MAX-NEEF, M.A. (2017): Economía herética. Treinta y cinco años a contracorriente, Icaria Editorial, Barcelona.

MAX-NEEF, M.A., ELIZALDE, A. \& HOPENHAYN, M. (1998): “Desarrollo y autodependencia”, En: Max-Neef, M.A., Desarrollo a escala humana, 83-116. Editorial Nordan-comunidad, Montevideo. https://www.max-neef.cl/

MOSANGINI, G. (2012): Decrecimiento y justicia Norte-Sur. 0 cómo evitar que el Norte Global condene a la humanidad al colapso, Icaria Editorial, Barcelona.

PAÑO, P. (2019): Economías étnicas locales, Amazonía y globalización. Estrategias etnoecológicas de comunidades amazónicas shuar del Ecuador, Universidad do Pará, Brasil.

PARIZEAU, K. (2011): “Un estudio acerca de la salud de los cartoneros en Buenos Aires. Peligro y desigualdad", En: Suárez, F.M. \& Schamber, P.J. (Comps.), Recicloscopio II. Miradas sobre recuperadores, políticas públicas y subjetividades en América Latina, 285-315. Universidad Nacional de General Sarmiento, Buenos Aires.

PARRA, F. (2011): "Bogotá y la coyuntura actual de manejo de residuos: un reto para la inclusión de población recicladora en el futuro manejo de los residuos de la ciudad", En: Suárez, F.M. \& Schamber, P.J. (Comps.), Recicloscopio II. Miradas sobre recuperadores, políticas públicas y subjetividades en América Latina, 33-54. Universidad Nacional de General Sarmiento, Buenos Aires. 
PAULI, G. (2015): La economía azul, Tusquets Editores, Barcelona.

PÉREZ OROZCO, A. (2015): “Prólogo: palabras vivas ante un sistema biocida”, En: D’ALISA, G., DEMARIA, F. \& KALLIS, G. (Eds.), Decrecimiento. Vocabulario para una nueva era, 27-33. Icaria Editorial, Barcelona.

PÉREZ OROZCO, A. (2017): Subversión feminista de la economía. Aportes para un debate sobre el conflicto capital-vida, Traficantes de sueños, Madrid.

QUIJANO, A. (2011): “Sistemas alternativos de producción?”, En: SANTOS, B. (Coord.), Producir para vivir. Los caminos de la producción no capitalista, 369-399. Fondo de Cultura Económica, México.

RAMOS, J. (2015): Sobre decrecimiento y economía del bioconocimiento, FLACSO Ecuador, Quito.

RAZETO, L. (2010): “Qué es la economía solidaria?”, PAPELES de relaciones ecosociales y cambio global, 110, 47-52.

REIKE, D., VERMEULEN, W.J.V. \& WITJES, S. (2018): "The circular economy: New or Refurbished as CE 3.0? - Exploring Controversies in the Conceptualization of the Circular Economy through a Focus on History and Resource Value Retention Options", Resources, Conservation and Recycling, 135, 246-264. D0I: 10.1016/j.resconrec.2017.08.027

RIECHMANN, J. (2007): “Oikos y Jaikus. Reflexiones sobre la crisis ecosocial”, En: LINZ, M., RIECHMANN, J. \& SEMPERE, J. (Coords.), Vivir (bien) con menos. Sobre suficiencia y sostenibilidad, 69-119. Icaria Editorial, Barcelona.

RODRÍGUEZ, C. (2011): "En busca de alternativas económicas en tiempos de globalización: el caso de las cooperativas de recicladores de basura en Colombia", En: Santos, B. (Coord.), Producir para vivir. Los caminos de la producción no capitalista, 255-285, Fondo de Cultura Económica, México.

RUGGERIO, C. (2011): “Cluster de plantas sociales de recuperación de residuos ¿Una oportunidad para propender a una gestión integral de los residuos sólidos urbanos? El Área Metropolitana de Buenos Aires como caso de estudio", En: Suárez, F.M. \& Schamber, P.J. (Comps.), Recicloscopio II. Miradas sobre recuperadores, políticas públicas y subjetividades en América Latina, 155-180. Universidad Nacional de General Sarmiento, Buenos Aires.

SANTOS, B. (2009): Una epistemología del sur, CLACSO Coediciones, México.

SANTOS, B. \& RODRÍGUEZ, C. (2011): "Para ampliar el canon de la producción", En: Santos, B. (Coord.), Producir para vivir. Los caminos de la producción no capitalista, 15-61. Fondo de Cultura Económica, México. 
SOLÍZ TORRES, M.F., YÉPEZ FUENTES, A. \& SACHER FRESLON, W. (2018): Fruta del norte. La manzana de la discordia, Ediciones La tierra, Ecuador. http://hdl.handle.net/10644/6217

SUBIRATS, J. [Resistiendo con Aguante]. (2018, Noviembre 20): CLACSO 2018 RESISTIENDO CON AGUANTE TV @RcaTv_0k [Video]. YouTube. Recuperado de https://www.youtube.com/watch?v=adLT2g86nsw

SURIÑACH, R. (2016): Les Altres Economies de la ciutat, Barcelona Activa, Barcelona.

SVAMPA, M. (2018): Debates Latinoamericanos. Indianismo, desarrollo, dependencia, populismo, Programa Democrático y Transformación Global, Lima.

TIROLE, J. (2017): La economía del bien común, Editorial Taurus, Barcelona.

TOLED0, V. (2015): "¿De qué hablamos cuando hablamos de sustentabilidad? Una propuesta ecológico política”, En: Cariño, M. \& Castorena, L. (Eds.), Saberes para la sustentabilidad, Icaria Editorial, Barcelona.

TRAINER, T. (2017): La vía de la simplicidad hacia un mundo sostenible y justo, Editorial Trotta, Madrid.

TRILLAS, A. (2019): “Las 7 vidas de un móvil y un jersey”, Alternativas económicas, 67, 13.

TRILLAS, A., LEÓN, C., RUSIÑOL, P., PEIRON, M., MARÍ, S. \& COLMENARES, M. (2019): “Cuadrar el círculo. La economía circular se propone convertir en una gran oportunidad de negocio el enorme desafío medioambiental que supone el modelo actual de comprar y tirar. Si se pone en marcha, exige cambios radicales en la manera de producir y consumir. ¿Va en serio o es un mero eslogan publicitario?" [Dossier], Alternativas económicas, 67, 35-47.

https://www.socioeco.org/bdf_fiche-document-6583_es.html

UNIÓN EUROPEA, (2017): Dictamen del Comité Europeo de las Regiones - Un plan de acción de la UE para la economía circular, Disponible en:

https://op.europa.eu/es/publication-detail/-/publication/e5e2c70b-0e01-11e7-8a3501aa75ed71a1.

VILLARÁN, M., CHÁVARRI, M., DIETRICH, T. \& RODRÍGUEZ, E. (2017): "Subproductos hortofrutícolas para una bioeconomía circular", Mediterráneo Económico, 31, 251-272.

WALLERSTEIN, I. (2014). El capitalismo histórico, Siglo XXI Editores, México. 